\title{
The Mycorrhiza-and Trichoderma-Mediated Elicitation of Secondary Metabolism and Modulation of Phytohormone Profile in Tomato Plants
}

\author{
Giusy Iula (D), Begoña Miras-Moreno *, Luigi Lucini (D) and Marco Trevisan (D) \\ Department for Sustainable Food Process, Università Cattolica del Sacro Cuore, Via Emilia Parmense 84, \\ 29122 Piacenza, Italy; giusy.iula@unicatt.it (G.I.); luigi.lucini@unicatt.it (L.L.); marco.trevisan@unicatt.it (M.T.) \\ * Correspondence: mariabegona.mirasmoreno@unicatt.it
}

check for updates

Citation: Iula, G.; Miras-Moreno, B.; Lucini, L.; Trevisan, M. The Mycorrhiza-and TrichodermaMediated Elicitation of Secondary Metabolism and Modulation of Phytohormone Profile in Tomato Plants. Horticulturae 2021, 7, 394. https://doi.org/10.3390/ horticulturae7100394

Academic Editor: Alessandra Francini

Received: 15 September 2021

Accepted: 8 October 2021

Published: 12 October 2021

Publisher's Note: MDPI stays neutral with regard to jurisdictional claims in published maps and institutional affiliations.

Copyright: (c) 2021 by the authors. Licensee MDPI, Basel, Switzerland. This article is an open access article distributed under the terms and conditions of the Creative Commons Attribution (CC BY) license (https:// creativecommons.org/licenses/by/ $4.0 /$ )

\begin{abstract}
Arbuscular mycorrhiza and Trichoderma are well-known beneficial fungi whose plant growth promotion and defense elicitation effects are known. However, the molecular and biochemical processes underlying the beneficial effects of these priming microorganisms have not been fully elucidated yet. On this basis, the present work aimed to use metabolomics to dissect comprehensively the modulation of secondary metabolism induced by mycorrhiza and Trichoderma, using tomato as a model plant. To this aim, either mycorrhiza or Trichoderma were applied to tomato roots at transplanting using a commercial formulation and then harvested once the mutualistic relationship was well established. Shoots were analyzed using an MS-based untargeted metabolomics approach, and differential metabolites identified by multivariate statistics were subjected to pathway analysis. Together with promoting plant growth, the treatments induced a broad molecular reprogramming with the phenylpropanoid biosynthetic pathway (including defense phenolics like coumarins and glycosylated anthocyanins) being strongly elicited. An accumulation of auxins, cytokinins, and jasmonate (especially after treatment with Trichoderma) could be observed concerning phytohormone profiles. Overall, the broad and distinctive effects triggered by mycorrhiza and Trichoderma in tomato secondary metabolism supported both plant growth promotion and immunity.
\end{abstract}

Keywords: biostimulants; plant growth promotion; metabolomics; phenylpropanoids; elicitors

\section{Introduction}

Increasing food demand, with a growing population and mounting environmental attention to the impact of agriculture, point to the next green revolution [1]. The purpose of this revolution is the increase of plant yield through more sustainable approaches. The use of biostimulants has emerged as one of the most promising eco-friendly strategies to reach the aim. A plant biostimulant is classified, according to the EU, as any substance or microorganism that, once applied to plants, can stimulate nutrient uptake, abiotic stress tolerance, and improve crop quality traits [2].

Among beneficial microorganisms, arbuscular mycorrhizal fungi (AMF) and Trichoderma spp. are widely used as plant biostimulants [3] to increase crop production due to their growth-stimulating effect(s) and control towards rhizospheric pathogens [4]. AMF promotes plant growth but also enhances photosynthesis [5], and elicits increasing resistance to abiotic stress, pests, and diseases [6]. Similarly, Trichoderma spp. are beneficial to plants due to their ability to boost crop nutrition, growth, and stress response, to induce resistance, and to produce fungal cell wall degrading enzymes $[7,8]$. The role of AMF and Trichoderma as plant biostimulants has been intensively studied $[9,10]$. The effect of AMF has been demonstrated to increase macronutrient $(\mathrm{N}, \mathrm{P}$, and $\mathrm{Fe}$ ) and micronutrient (Mn and $\mathrm{Zn}$ ) uptake and assimilation, enhance plant growth and root apparatus development, boost photosynthetic activity, release low-and high-molecular-weight organic compounds, and shape phytohormone profiles [11]. However, the mechanisms by which Trichoderma spp. 
acts as biostimulant involve the production of mitogen-activated proteins, auxin, phenylpropanoids, and phytoalexins production, release of volatile and non-volatile substances, molecules that act in increasing plant survival and nutrient uptake [12-14]. Different studies have demonstrated the biostimulant activity of Trichoderma and AMF in plants and their ability to promote acclimation to stress $[15,16]$. However, the molecular and biochemical mechanisms underlying the action of these microorganisms as priming agents have not been fully elucidated. The comprehensive characterization of the metabolomic reprogramming these microorganisms can induce in the plant could shed light on the molecular basis of the complex interaction between plant and AMF/Trichoderma [17].

In fact, it is expected that the biostimulant treatments can trigger a broad molecular reprogramming of secondary metabolism. To this aim, tomato (Solanum lycopersicum L.) has been selected as a model plant due to its economic interest and diverse secondary metabolism. Tomato is the second most important vegetable crop in the world after potato [18], with a worldwide production of 180 million tons in 2019 [19]. This work focuses on secondary metabolism as a fundamental part of plant response to the environment, including abiotic and biotic stresses, and aims for a comparative investigation of the elicitation processes triggered by either AMF or Trichoderma.

\section{Materials and Methods}

\subsection{Growth Conditions, Plant Material, and Treatments}

Tomato plants (Solanum lycopersicum, cultivar Heinz 1301) were supplied by a local nursery at the three true leaves stage, devoid of chemical or microbiological treatments and grown in the greenhouse situated at Università Cattolica del Sacro Cuore, Piacenza, Italy. Homogenous and healthy plants were immediately transplanted into $40 \mathrm{~cm}$ pots using a commercial loam substrate (Compo star, $\mathrm{pH}=6.1$ in water, EC $0.6 \mathrm{dS} / \mathrm{m}$, density $375 \mathrm{~kg} / \mathrm{m}^{3}$, and porosity $80 \% \mathrm{v} / \mathrm{v}$ ) in the middle of April. Ten different pots per treatment, each comprising 3 plants, were prepared with a randomized design. The plants were grown under controlled conditions, with temperatures between $18-25^{\circ} \mathrm{C} \pm 2{ }^{\circ} \mathrm{C}\left(18{ }^{\circ} \mathrm{C}\right.$ in dark and $25{ }^{\circ} \mathrm{C}$ during light) and the photoperiod $16 \mathrm{~h}$ light $/ 8 \mathrm{~h}$ darkness. The pots were watered with $2 \mathrm{~L}$ of water every $3-4$ days. $2 \mathrm{~L}$ of basic nutrient solution $(13 \mathrm{mmol} / \mathrm{L}$ $\mathrm{NO}_{3}-\mathrm{N}, 1 \mathrm{mmol} / \mathrm{L} \mathrm{NH}_{4}-\mathrm{N}, 1.75 \mathrm{mmol} / \mathrm{L} \mathrm{S}, 1.5 \mathrm{mmol} / \mathrm{L} \mathrm{P}, 5 \mathrm{mmol} / \mathrm{L} \mathrm{K}, 4.5 \mathrm{mmol} / \mathrm{L} \mathrm{Ca}$, $2 \mathrm{mmol} / \mathrm{L} \mathrm{Mg}, 1 \mathrm{mmol} / \mathrm{L} \mathrm{Na}, 1 \mathrm{mmol} / \mathrm{L} \mathrm{Cl}, 20 \mu \mathrm{mol} / \mathrm{L} \mathrm{Fe}, 9 \mu \mathrm{mol} / \mathrm{L} \mathrm{Mn}, 0.3 \mu \mathrm{mol} / \mathrm{L}$ $\mathrm{Cu}, 1.6 \mu \mathrm{mol} / \mathrm{L} \mathrm{Zn}, 20 \mu \mathrm{mol} / \mathrm{L} \mathrm{B}$, and $0.3 \mu \mathrm{mol} / \mathrm{L} \mathrm{Mo})$, with an electrical conductivity of $2.0 \mathrm{dS} / \mathrm{m}$, was applied at 15 days after transplantation.

At the growth stage, BBCH19 (9 leaves on the main shoot unfolded), tomato plants were treated using either the commercial formulation Condor Shield (Trichoderma koningii TK7, $1 \times 109$ CFU/g) or Aegis Sym irriga (Rhizoglomus irregulare BEG72 and Funneliformis mosseae BEG234, $700 \mathrm{sp} / \mathrm{g}$ each species), both from Atens-Agrotecnologias Naturales SL (Tarragona, Spain). The application of the formulations was made according to label recommendations, one application at the dosage of 1.0 and $0.1 \mathrm{~g} /$ plant for Trichoderma and AMF, respectively. Tomato plants inoculated with Trichoderma koninjii were harvested after 15 days, while plants inoculated with mycorrhiza were harvested 30 days after treatments (DAT). Control plants were left untreated and harvested at both 15 and 30 days. The sampling dates corresponded with the manufacturer's recommendation to achieve a consolidated symbiosis.

\subsection{Plant Biomass and Metabolomic Analysis by UHPLC/QTOF-MS}

At the scheduled sampling point, plant leaves from three pots were used for biomass determination. To this aim, 10 randomly collected leaves from each plant were used for biomass determination, with triplicate measurements. Dry weight (g), fresh weight (g), and their ratio (as biomass index, \%) were determined in plants treated with AMF, Trichoderma, and untreated plants. Forced ventilation was used for dry weight determination for $72 \mathrm{~h}$ at $80^{\circ} \mathrm{C}$, until reaching constant weight. 
The plants from six pots (not used for biomass) were quenched and homogenized in liquid nitrogen using pestle and mortar and stored at $-80^{\circ} \mathrm{C}$. Each pot represented an experimental unit $(n=6)$, where the aerial parts of the three plants were pooled. Tissues were extracted in acidified $80 \%$ methanol, as previously reported [20]. The samples were extracted by Ultra- Turrax (Ika T-25; Staufen, Germany), centrifuged and filtered through a $0.22 \mu \mathrm{m}$ cellulose membrane into vials for analysis. A UHPLC chromatographic system coupled to a quadrupole-time-of-flight mass spectrometer (UHPLC/QTOF-MS) was used for the untargeted screening of metabolites [21]. A linear gradient made from acetonitrile (from $6 \%$ to $94 \%$ organic within $33 \mathrm{~min}$ ) in water, a flow rate of $200 \mu \mathrm{L} \mathrm{min}{ }^{-1}$, and a PFP column $(2.0 \times 100 \mathrm{~mm}, 3 \mu \mathrm{m}$-Agilent technologies, Santa Clara, CA) were used for chromatography. Concerning high-resolution mass spectrometry, the QTOF operated in SCAN mode (positive polarity, 100-1200 m/z range) and extended dynamic range mode. To analyse quality controls (QCs), data-dependent MS/MS was adopted, selecting 12 precursors per cycle $(1 \mathrm{~Hz}, 50-1200 \mathrm{~m} / \mathrm{z}$, positive polarity, active exclusion after 2 spectra), with collision energies of 10, 20, and $40 \mathrm{eV}$ for collision-induced decomposition [22].

The software Profinder B.07 (from Agilent Technologies) was required for deconvolution, mass, retention time alignment, and filtering (mass accuracy $<5 \mathrm{ppm}$ ) [23]. The database PlantCyc 12.6 (Plant Metabolic Network, http:/ / www.plantcyc.org; accessed on 18 April 2020) was used for compound identification, according to a level 2 of COSMOS confidence in annotation [24], based on accurate mass, isotope spacing, and isotope ratio. QCs tandem MS spectra were processed using the software MS-DIAL 4.24 [25], to strengthen annotation. Public MS/MS experimental spectra built into the software (MoNA-Mass Bank of North America) and in silico fragmentation patterns were used to perform the annotation [26,27].

\subsection{Statistical Analysis}

To analyse biomass data, a one-way analysis of variance (ANOVA) was carried out ( $p<0.05$, Duncan's posthoc test) in IBM PASW Statistics 26.0 (SPSS, New Yosk, NY, USA). A chemometric interpretation of metabolomics was performed using the software Mass Profiler Professional 12.6 (Agilent Technologies), according to Corrato et al. [28]. Compound filtering by abundance (area $>5000$ counts), baselining to the median of each compound and normalization at the 75th percentile, were carried out before statistics. After that, a FC-based hierarchical cluster analysis (Euclidean distance, Ward's linkage rule) was carried out for unsupervised distribution to investigate relatedness/unrelatedness between treatments. A supervised OPLS-DA modelling was next performed in SIMCA 16 (Umetrics; Malmo, Sweden) following Hotelling's T2 test for outliers (with 95\% and 99\% confidence limits for suspect and strong outliers). CV-ANOVA $(p<0.01)$ cross-validation and permutation testing $(\mathrm{N}=100)$ for overfitting were also carried out before OPLS-DA modelling. Thereafter, model fitness (goodness-of-fit, $R^{2} Y$, and goodness-of-prediction, $Q^{2} Y$ ) were recorded, and the most discriminant compounds identified by the Variable Importance in Projection (VIP) analysis (VIP score > 1.3) [28]. Finally, ANOVA followed by FC analysis was carried out ( $p<0.01$, Bonferroni multiple testing correction; FC analysis $\geq 1.5$ ) to identify differential compounds; these were later imported into the Omic Viewer Pathway Tool of PlantCyc software (Stanford, CA, USA) [29].

\section{Results}

\subsection{Biomass Production}

Tomato leaves were collected and used for the determination of plant biomass. Dry weight $(\mathrm{g})$ and fresh weight $(\mathrm{g})$ were recorded, and their ratio (biomass index, \%) calculated, to be used as a growth index (Table 1). Trichoderma promoted a significant $(p<0.05)$ increase in dry biomass, whereas AMF significantly increased dry and fresh weight. The biomass increase, in all cases, was around 1.3 fold. The biomass index of plants treated using Trichoderma was $24.8 \%$, compared to $17.5 \%$ of control. However, the biomass index of plants treated with AMF was $21.4 \%$, while control was $20.3 \%$. 
Table 1. Biomass data for tomato plants treated with AMF and Trichoderma with statistical parameters.

\begin{tabular}{ccccc}
\hline & \multicolumn{2}{c}{ Fresh Weight (g) } & \multicolumn{2}{c}{ Dry Weight (g) } \\
& $\begin{array}{c}\text { Average } \\
\text { (Mean } \pm \text { Standard } \\
\text { Deviation) }\end{array}$ & $\begin{array}{c}\text { 95\% } \\
\text { Confidence } \\
\text { Interval (g) }\end{array}$ & $\begin{array}{c}\text { Average } \\
\text { (Mean } \pm \text { Standard } \\
\text { Deviation) }\end{array}$ & $\begin{array}{c}\text { 95\% } \\
\text { Confidence } \\
\text { Interval (g) }\end{array}$ \\
\hline $\begin{array}{c}\text { Trichoderma, control } \\
\text { Trichoderma, treated }\end{array}$ & $1.71 \pm 0.04$ & $1.61-1.81$ & $0.30 \pm 0.02$ & $0.25-0.35$ \\
\hline Fold-change & $1.65 \pm 0.04$ & $1.55-1.76$ & $0.41 \pm 0.02$ & $0.36-0.46$ \\
\hline$p$-value & \multicolumn{2}{c}{0.96} & \multicolumn{2}{c}{0.003} \\
\hline AMF, control & $1.49 \pm 0.03$ & $1.43-1.56$ & $0.30 \pm 0.02$ & $0.25-0.36$ \\
AMF, treated & $1.86 \pm 0.05$ & $1.73-1.98$ & $0.40 \pm 0.02$ & $0.34-0.45$ \\
\hline Fold-change & \multicolumn{2}{c}{1.148} & \multicolumn{2}{c}{1.33} \\
\hline$p$-value & \multicolumn{2}{c}{0.007} \\
\hline
\end{tabular}

\subsection{Effect of AMF and Trichoderma on Tomato Metabolism and Phytohormone Profile}

Tomato leaf extracts were analyzed by liquid chromatography high-resolution mass spectrometry (UHPLC/QTOF-MS) to unravel how the metabolic profiling was influenced when a symbiosis was established between the tomato plant and Trichoderma or AMF. In total, more than 3000 molecular features were annotated. The whole dataset, including individual abundances and composite mass spectra for all the features, is provided as supplementary material (Table S1). The multivariate approach, hierarchical cluster analysis, was initially used to investigate relatedness/unrelatedness between treatments in an unsupervised manner, based on the fold-change derived heatmap (Figure 1). The clusters produced enabled the identification of four clusters, each of which included all replications within a treatment. This indicates that the effect of treatment on the metabolomic profile was hierarchically stronger than the biological variability across plants. Furthermore, both treatments demonstrated a different metabolic profile compared to the control plants. Despite imposing a comparatively lower increase in biomass, Trichoderma application was the most distinctive treatment in terms of secondary metabolism reprogramming.

The unsupervised clustering has been confirmed by orthogonal projection to latent structures discriminant analysis (OPLS-DA) supervised modeling, where the samples were separated in the score plot space (Figure 2).

Both control samples clustered together in the OPLS hyperspace, while the treatment with Trichoderma or AMF separated apart in the score plot. This supervised modelling further confirmed that the treatments elicited differential modulation of molecular pathways. The OPLS-DA model was validated by regression parameters, with the goodness-of-fit $\mathrm{R}^{2} \mathrm{Y}$ (correlation) and goodness-of-prediction $\mathrm{Q}^{2} \mathrm{Y}$ (prediction ability) being 0.99 and 0.9 , respectively. Moreover, CV- ANOVA $(p<0.001)$ was acceptable, and overfitting could be excluded.

The Variable Importance in Projection (VIP) analysis was performed to identify the compounds with the highest discrimination potential, adopting a VIP score threshold of $>1.3$. This screening led to the identification of 158 marker compounds (Table S2). The most representative biochemical classes were related to fatty acid and lipid biosynthesis, phenylpropanoid derivative biosynthesis, phytoalexin compounds, and hormone biosynthesis.

To unravel the biochemical reprogramming that occurred after microorganism application, differential compounds derived from the ANOVA and fold-change (FC) analysis were then interpreted using the Omic Viewer Pathway Tool (Table S3). Overall, more than 150 metabolites were involved in several biosynthetic pathways (Figure 3A and Table 2), with secondary metabolism emerging as the most affected by the treatments (Figure 3B and Table 3). 

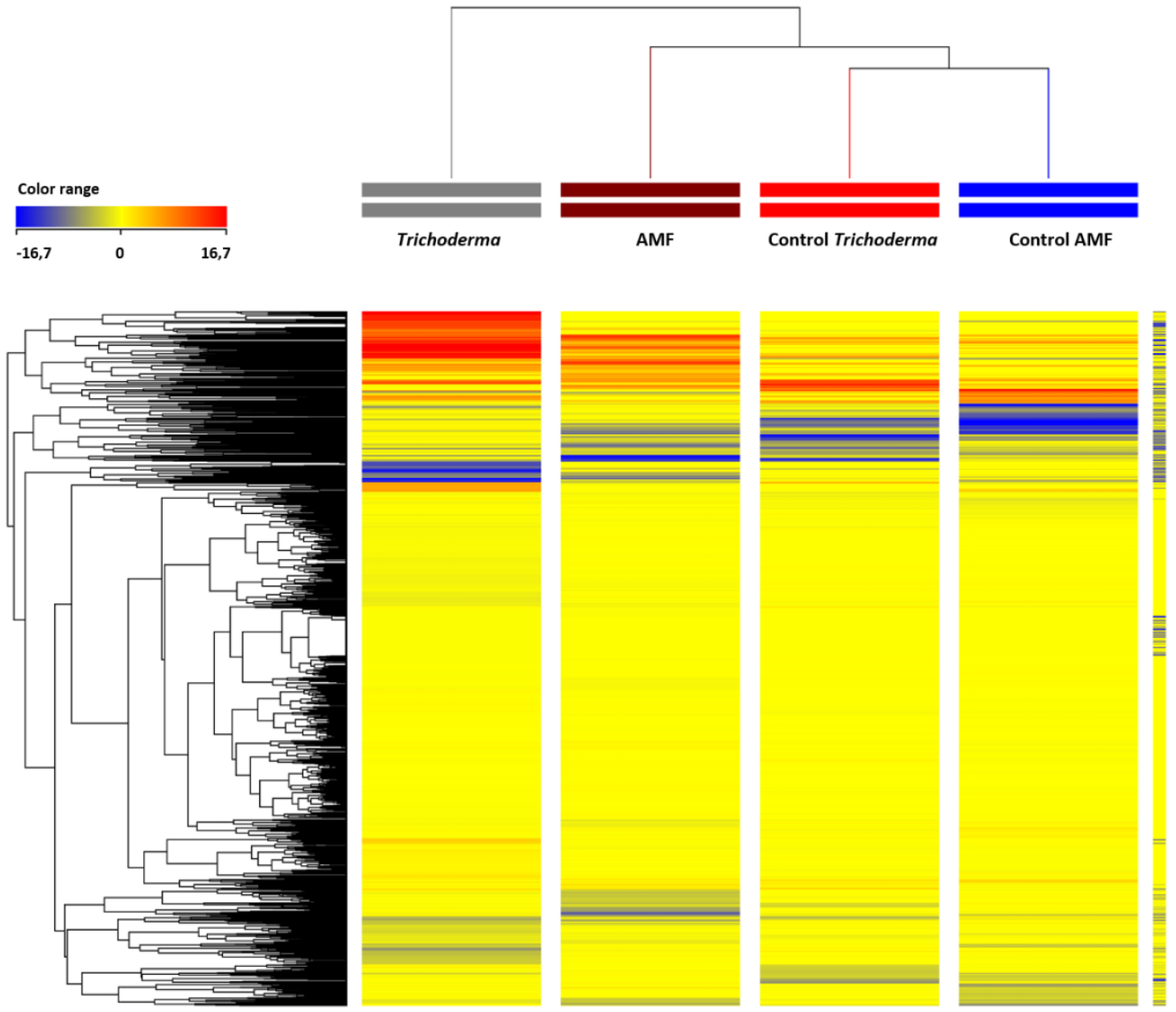

Figure 1. Unsupervised hierarchical cluster analysis (Euclidean distance; linkage rule: Ward) of tomato leaf chemical profiles after biostimulant treatments. Metabolites were obtained by UHPLCESI/QTOF-MS untargeted analysis, and their intensities were used to create the fold-change heat map provided here. The color range represents the fold-change values used to build the heat-map (the color range is provided in Figure 1).

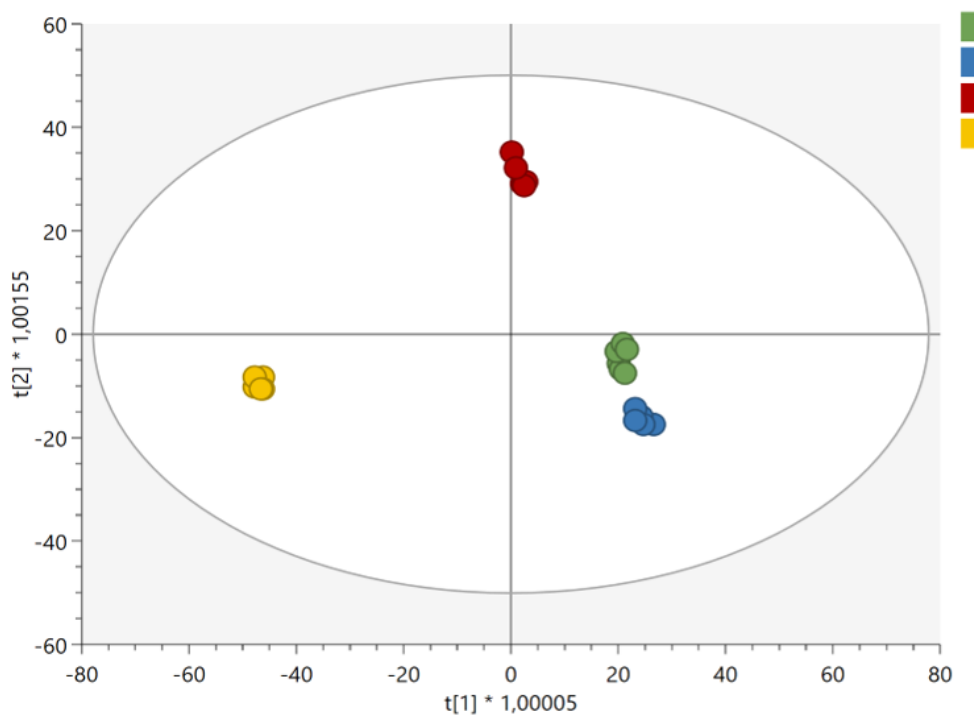

Control Trichoderma

Control AMF

AMF

Trichoderma

Figure 2. Score plot in the first ( $x$-axis) and second ( $y$-axis) latent vector of orthogonal projection to latent structures discriminant analysis (OPLS-DA) supervised modeling carried out on metabolomic profiles of tomato leaves after treatment with Trichoderma, AMF, and control samples $\left(R^{2} Y=0.8\right.$, $\left.\mathrm{Q}^{2} \mathrm{Y}=0.99\right)$. 
A

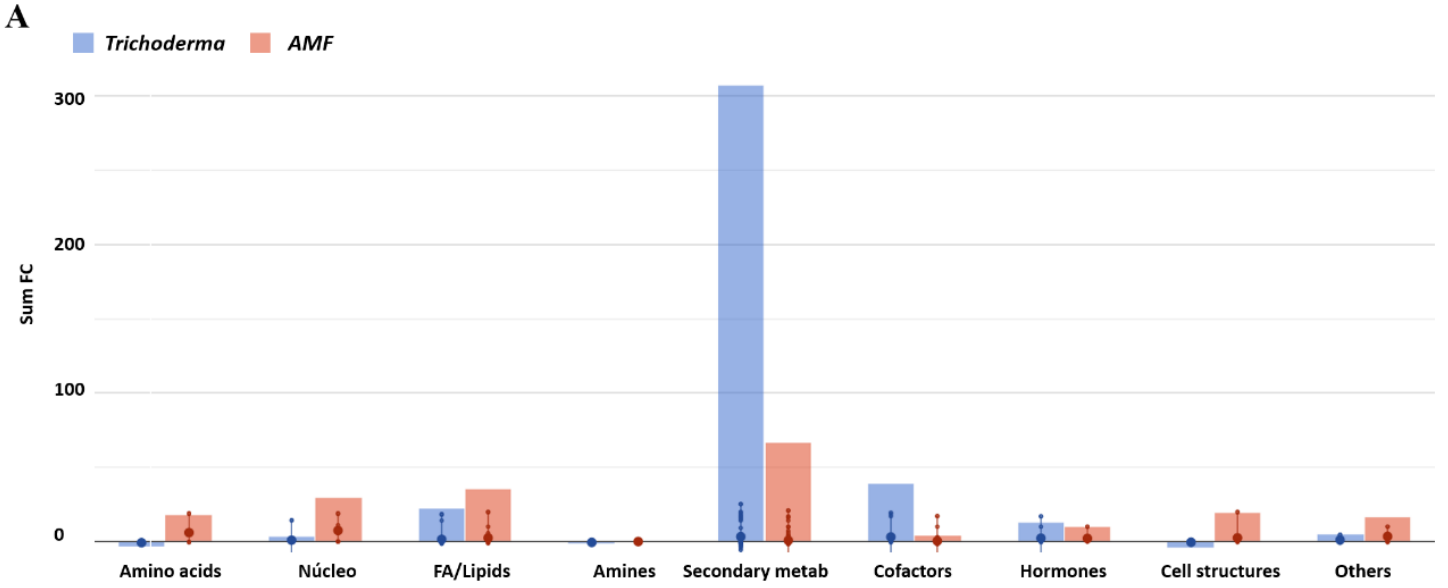

B

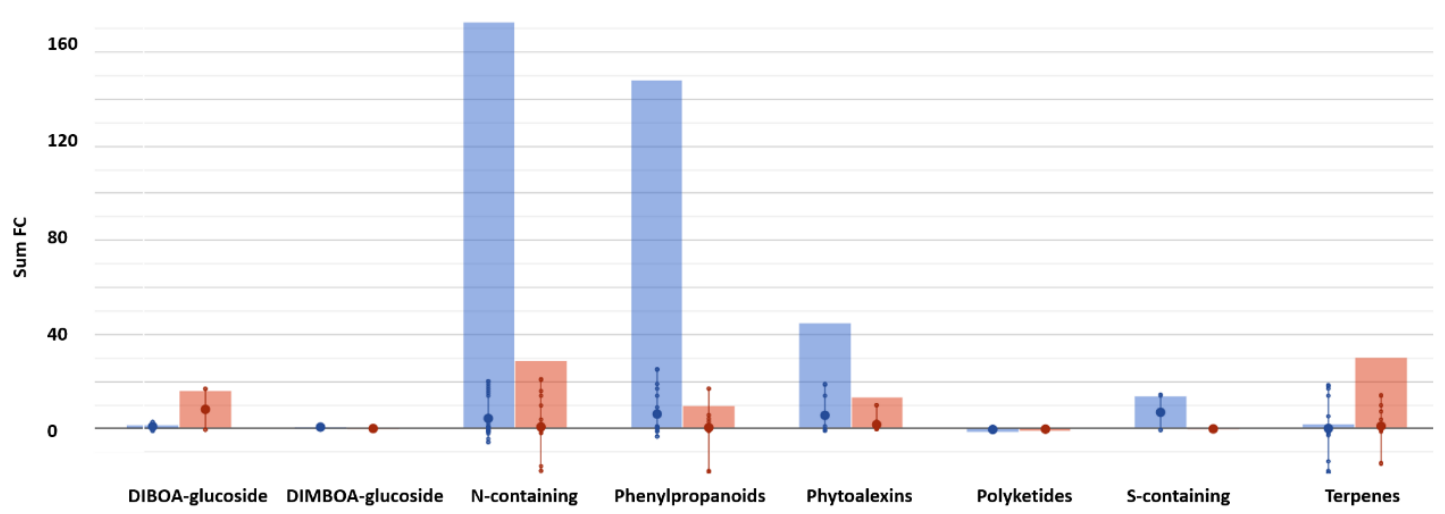

Figure 3. Metabolic processes (A) and secondary metabolite biosynthesis (B) were impaired in tomato leaves as a result of the treatments. The metabolomics dataset produced through UHPLC-ESI/QTOF-MS was subjected to ANOVA followed by a fold-change (FC) $(p<0.05, \mathrm{FC} \geq 1.5)$, and differential metabolites were loaded into the PlantCyc Pathway Tool (https:/ / www.plantcyc.org/, accessed on 18 April 2020). The $x$-axis represents each set of metabolic subcategories, while the $y$-axis corresponds to the cumulative log FC. The large dots represent the average (mean) of all FCs for the different metabolites in the class, while the small dots represent the individual log FC.

Among others, compounds belonged to nitrogen-containing secondary metabolites, terpenoids (geranyl-geranyl-diphosphate and farnesyl-diphosphate, following AMF treatment), fatty acids and stearate (in particular following AMF treatment), phospholipids and phenylpropanoid derivatives, as well as glucosinolates and phytoalexins (the benzoxazinoid HBOA rather than pinosylvin and maackiain, following AMF and Trichoderma respectively).

The discriminant compounds from the phenylpropanoid derivative biosynthetic pathway were coumarins such as 4-coumaraldehyde, 4-coumaryl-4-coumarate, bergaptol (a linear furanocoumarin precursor), umbelliferone, and trans- caffeate. Also, bis-noryangonin (one of the resveratrol precursors) strongly accumulated in treated plants. These pathways were elicited after inoculation of both AMF and Tricoderma treatments; while, only in plants treated with Trichoderma, the pathway of podophyllotoxin glucoside production, was elicited together with an up-accumulation of anthocyanins, particularly cyanidin $3-O-(\beta-\mathrm{D}-x y l o s y l-(1 \rightarrow 2)-\beta$ D-galactoside) and delphinidin 3-O-glucosyl-5-O-(caffeoylglucoside-3'-O-glucoside).

As for what concerns the hormonal profile in both treatments, significant changes could be observed in the auxin group, involving (indol-3-yl)acetate, $\alpha$ - $\beta$-D-glucosyl-(indol3 -yl)acetate, and (indol-3-yl)acetyl-L-isoleucine. Moreover, jasmonate derivates such as jasmonoyl-L-isoleucine inactivation and (-)-jasmonoyl-1-aminocyclopropane-1 carboxylate were highlighted among differential compounds. Of note, despite also displaying microorganism-specific response(s), the secondary metabolisms elicited by the treatments were largely shared between Trichoderma and AMF. 
Table 2. Metabolic processes altered in tomato leaves as a result of the treatments, expressed as the total number of compounds, average of log fold-change (FC) and sum of log FC. The metabolomics dataset produced through UHPLCESI/QTOF-MS was subjected to ANOVA followed by FC analysis $(p<0.05, \mathrm{FC} \geq 1.5)$, and differential metabolites were loaded into the PlantCyc Pathway Tool (https://www.plantcyc.org/, accessed on 18 April 2020).

\begin{tabular}{|c|c|c|c|c|c|c|}
\hline \multirow[b]{2}{*}{ Pathway } & \multicolumn{3}{|c|}{ Trichoderma } & \multicolumn{3}{|c|}{ AMF } \\
\hline & $\begin{array}{l}\text { Number of } \\
\text { Compounds }\end{array}$ & $\begin{array}{l}\text { Average } \\
\text { FC }\end{array}$ & $\begin{array}{l}\text { Sum } \\
\text { FC }\end{array}$ & $\begin{array}{l}\text { Number of } \\
\text { Compounds }\end{array}$ & $\begin{array}{l}\text { Average } \\
\text { FC }\end{array}$ & $\begin{array}{l}\text { Sum } \\
\text { FC }\end{array}$ \\
\hline Amino Acid Biosynthesis & 4 & -0.84 & -3.37 & 3 & 5.94 & 17.82 \\
\hline $\begin{array}{c}\text { Nucleosides and Nucleotides } \\
\text { Biosynthesis }\end{array}$ & 4 & 0.87 & 3.46 & 4 & 7.38 & 29.52 \\
\hline $\begin{array}{c}\text { Fatty Acid and Lipid } \\
\text { Biosynthesis }\end{array}$ & 16 & 1.40 & 22.37 & 15 & 2.38 & 35.73 \\
\hline $\begin{array}{c}\text { Amines and Polyamines } \\
\text { Biosynthesis }\end{array}$ & 2 & -0.66 & -1.31 & 1 & -0.08 & -0.08 \\
\hline $\begin{array}{l}\text { Secondary Metabolites } \\
\text { Biosynthesis }\end{array}$ & 97 & 3.17 & 307.54 & 98 & 0.68 & 66.79 \\
\hline $\begin{array}{l}\text { Cofactors, Prosthetic Groups, } \\
\text { Electron Carriers Biosynthesis }\end{array}$ & 13 & 3.00 & 39.07 & 13 & 0.33 & 4.30 \\
\hline Hormones Biosynthesis & 6 & 2.17 & 13.04 & 5 & 2.01 & 10.06 \\
\hline Cell Structures Biosynthesis & 8 & 0.58 & -4.32 & 8 & 2.41 & 19.29 \\
\hline Other Biosynthesis & 5 & 1.05 & 5.24 & 5 & 3.37 & 16.83 \\
\hline
\end{tabular}

Table 3. Secondary metabolites altered in tomato leaves as a result of the treatments, expressed as total number of compounds, average of log fold-change (FC), and sum of log FC. The metabolomics dataset produced through UHPLCESI/QTOF-MS was subjected to ANOVA followed by a FC analysis $(p<0.05$, fold change $\geq 1.5)$, and differential metabolites were loaded into the PlantCyc Pathway Tool (https:/ / www.plantcyc.org/, accessed on 18 April 2020).

\begin{tabular}{|c|c|c|c|c|c|c|}
\hline \multirow[b]{2}{*}{ Pathway } & \multicolumn{3}{|c|}{ Trichoderma } & \multicolumn{3}{|c|}{ AMF } \\
\hline & $\begin{array}{l}\text { Number of } \\
\text { Compounds }\end{array}$ & $\begin{array}{l}\text { Average } \\
\text { FC }\end{array}$ & $\begin{array}{l}\text { Sum } \\
\text { FC }\end{array}$ & $\begin{array}{l}\text { Number of } \\
\text { Compounds }\end{array}$ & $\begin{array}{l}\text { Average } \\
\text { FC }\end{array}$ & $\begin{array}{c}\text { Sum } \\
\text { FC }\end{array}$ \\
\hline DIBOA-glucoside biosynthesis & 2 & 0.89 & 1.77 & 2 & 8.17 & 16.33 \\
\hline $\begin{array}{l}\text { DIMBOA-glucoside } \\
\text { biosynthesis }\end{array}$ & 1 & 0.61 & 0.61 & 1 & 0.01 & 0.01 \\
\hline $\begin{array}{c}\text { Nitrogen-Containing } \\
\text { Secondary Compound } \\
\text { Biosynthesis }\end{array}$ & 40 & 4.32 & 172.86 & 42 & 0.69 & 29.09 \\
\hline $\begin{array}{c}\text { Phenylpropanoid Derivative } \\
\text { Biosynthesis }\end{array}$ & 24 & 6.17 & 148.03 & 24 & 0.41 & 9.83 \\
\hline Phytoalexin Biosynthesis & 8 & 5.63 & 45.01 & 8 & 1.68 & 13.40 \\
\hline Polyketide Biosynthesis & 4 & -0.40 & -1.60 & 4 & -0.24 & -0.97 \\
\hline $\begin{array}{l}\text { Sulfur-Containing Secondary } \\
\text { Compound Biosynthesis }\end{array}$ & 2 & 6.91 & 13.82 & 2 & -0.14 & -0.28 \\
\hline Terpenoid Biosynthesis & 30 & 0.06 & 1.82 & 30 & 1.01 & 30.39 \\
\hline
\end{tabular}

\section{Discussion}

The beneficial effects of endophytic fungi like mycorrhiza (AMF) and Trichoderma in agriculture are well known. In particular, both were found to be good modulators of root system development, nutrient uptake, plant stress response, and production of secondary metabolites [30].

In this work, the positive effect of endophytic fungi on tomato growth has been confirmed by improved leaf biomass production, compared to untreated tomato plants. Notably, this result fits with the literature, where the ability of both Trichoderma and AMF to promote plant growth is reported [9,31-33]. The symbiotic relationship between plant roots and AMF/Trichoderma may increase nutrient uptake and translocation, thus leading 
to higher biomass production $[9,10,34,35]$. Under our conditions, the treatment with Trichoderma was more effective in promoting leaves biomass than the treatment with AMF.

Provided the expected effect on leaf growth, a metabolomic investigation was next used to unravel the shaping of the secondary metabolism elicited by the symbiosis with endophytic fungi. Despite being only partially implicated in plant growth, the modulation of secondary metabolism may provide insights on the ability of plants to deal with abiotic and biotic stresses and may contribute to explaining the effects on plant structure. Interestingly, a profound modulation of plant secondary metabolism could be highlighted in our experiments following colonization by endophytic fungi. To date, most of the literature were based on genetic approaches or molecular studies [36,37]. Our metabolomics results complement the previous information by providing chemotype information that is closer to the phenotype. Our multivariate statistics demonstrated that most discriminant compounds belong to the plant's secondary metabolism, with significant involvement of stress response processes that included plant immune response.

The elicitation of phenylpropanoid biosynthesis, with coumarins as a key player, represents an example of such stress response processes. Coumarins belong to the class of lactones characterized by a benzene ring fused to a $\alpha$-pyrone ring, thus having a conjugated electron system with good charge-transport properties [38]. Coumarins have roles in plant defences, abiotic stress response, oxidative stress response, and likely they also impact hormonal regulation [39]. Among phenylpropanoids, the pathway of podophyllotoxin glucoside metabolism was triggered by Trichoderma. Although this was unexpected, there are 121 R2R3MYB TF-related genes in tomato, regulated by MYB transcription factors, responsible for activating the gene encoding for podophyllotoxin in Podophyllum species [40,41]. Nonetheless, stress conditions caused by inoculation with Trichoderma are known to lead to the activation of genes that were normally silent in tomato [40]. Still, among phenylpropanoids, the anthocyanins and their glycosylated form were significantly increased in response to AMF/Trichoderma. Together with attracting pollinators, anthocyanins protect plants from both biotic and abiotic stresses [42]. The higher anthocyanin concentration was directly correlated to AMF/Trichoderma colonization, likely as a consequence of the activation of a plant's defense response [43,44].

The systemic acquired resistance (SAR) and induced systemic resistance (ISR) defence mechanisms were activated in plants in response to biotic stress [45]. The systemic response involves the de novo production of phytoalexin compounds [46]. The concept of phytoalexins was introduced over 70 years ago [47] and refers to a group of diverse broad-spectrum antimicrobial compounds. Phytoalexins can be produced via the phenylpropanoid pathway, through the mevalonic acid pathway, and the Trp pathway [48]. The knowledge of the biosynthetic pathways of phytoalexins and the involved enzymes help to understand how plant defense response is activated upon infection by pathogens [49]. In this work among phytoalexins, the accumulation of bis-noryangonin, a precursor of resveratrol [50], could be highlighted. Resveratrol has been recognized as a stilbene-type phytoalexin [51,52] and represents a parent compound of a family of molecules expressing antifungal activity [53]. The accumulation of bis-noryangonin is consistent with the elicitation of coumarins, since the two pathways share common metabolites. The function of phytoalexins in plant defense is well documented in the literature [47] and their production is known to be increased after AMF and Trichoderma treatment [30]. These compounds are part of the ISR, which is triggered not only by pathogens but also by symbiotic microorganisms [54,55], including AMF and Trichoderma [10,56]. The plant response to microorganisms can switch the phenylpropanoids biosynthetic pathway at the level of the shikimate core unit, an important branchpoint originating from 4-coumaroyl CoA $[57,58]$. In the presence of stress, plants can redirect the entire phenylpropanoid pathway towards producing phytoalexins, volatiles, flavonoids, and anthocyanins [57].

Another interesting pathway result to be remodulated, especially after Trichoderma treatment, is the biosynthesis of gluocosinolates. It is known that glucosinolates, both aliphatic and indole, are involved in plant defense response, mainly against herbivores [59]. 
Glucosinolates are involved in the detoxification of glutathione (GSH), a pathway essential to mitigate the cell damage of reactive oxygen species (ROS) [60]. This result matches with the literature; for example, in Cucurbitaceae treated with a vegetal biopolymerbased biostimulant, the glucosinolates were the main classes of differential compounds founded [61]. In another work, zucchini squash (Cucurbita pepo L.) was treated with Trichoderma spp., finding the biosynthesis of glucosinolates the key player in enhancing plant defenses [12].

AMF and Trichoderma inoculation leads also to alteration in the production of epoxysqualene, fatty acids, phospholipids, sterols, and sphingolipids, indicating an evident modulation of lipid [21] and terpene [62] profile. Sterols are components of the membrane lipid bilayer, and their role ranges from regulation of growth to stress resistance [62]. Particularly, it has been reported that the accumulation of plant sterols is a strain-dependent feature among fungal elicitors [63]. The tomato cyclopropyl isomerase, an enzyme involved in sterol biosynthesis interacting with the LeEix2 receptor, is an important factor in regulating the induction of hypersensitive response, ethylene biosynthesis, and pathogenesis-related protein expression $[64,65]$. The alteration of the sterol composition of plant cell membrane leads to a reduction in the LeEix internalization, decreasing the induction of plant defense responses [66].

Also, phospholipid and sphingolipid profiles were modified by the treatment. This was in line with the literature [13] and their role as plasma membrane components such as signaling, membrane trafficking, and apoptosis [67]. The sphingolipid biosynthetic pathway was activated, especially after AMF inoculation with compounds such as 3dehydrosphinganine (C18) and sphinganine 1-phosphate. Sphingolipidis have a critical role in biotic stress [68], particularly against bacterial and fungal pathogens, bringing the cell to programmed cell death [68]. Sphingolipids are also elicitors in plant-microbe interactions [69]. During the establishment of plant-microbe symbiosis, a cuticular wax is formed on the leaf epidermis from a mixture of higher alkanes and lipids [69]. These compounds have not only the function as physical barriers, but they are also signaling molecules or alternatively provide elicitors (PAMP/MAMP). The PAMP/MAMP are recognized by plasma membrane-resident pattern recognition receptors (PR), activating the plant's defenses [69]; therefore, it seems that, in this study, sphingolipids also play important roles as signal molecules to induce a plant's defenses.

The hypothesis is that, after inoculation of AMF/Trichoderma in tomato, plants activated their first layer of defense mechanism, leading to up-regulation of phytosterol biosynthetic pathways with the induction of change in the membrane lipid bilayer composition. Spatio-temporal changes in the membrane's lipid profile connect the perception of pathogens with the activation of plant immunity [70]; the changes in lipid profile also impact the production of sphingolipid as molecular elicitors [69].

Also of note, phytohormone profiles changed upon AMF/Trichoderma inoculation, with auxins, cytokinins (CK), and jasmonates (JA) being highlighted among discriminant hormones. Plant hormones are implied in regulating developmental processes and a wide range of biotic and abiotic stresses [71]. Nonetheless, plant hormones are important signal molecules for controlling plant defense responses [72]. The modulation of CK is involved in processes such as stem cell control, vascular differentiation, chloroplast biogenesis, seed development, growth and branching of the root, shoot and inflorescence, leaf senescence, nutrient balance, and stress tolerance [73]. Plant pathogens can induce CK production in the host plant, and, in turn, CK activates the plant defense machinery and promotes pathogen resistance by inducing immunity in the host [74]. Similarly, the elicitation of both auxins and jasmonates pointed to the involvement of both plant growth and defense responses [72]. In particular, JA is typically implicated in the plants' response against herbivore and pathogen attack [75]. Moreover, JA also represents a major player in regulating systemic immunity conferred by beneficial microorganisms [76]. In contrast, auxins constitute plant hormones typically related to growth and may have been involved (together with $\mathrm{CK}$ ) in improved biomass accumulation. In fact, auxins improve nitrogen 
metabolism [77] and root growth in interaction with other phytohormone signaling [78]. More recently, together with regulating plant growth processes and the response to abiotic stresses, the role of auxins emerged in plant-pathogen interactions as well. The role of auxins in plant immunity involves balancing immune responses and fitness costs [79], and the suppression of auxin signaling is part of plant resistance to bacteria [80]. However, an active auxin perception is required for an effective AMF and Trichoderma symbiosis [81]. Indeed, several auxin-responsive genes, such as GH3, are reported to be induced in tomato roots following AMF colonization [82], and the coordinated increase of auxins and CK is pivotal in the establishment of the symbiosis [83,84]. With this regard, it was reported that ectomycorrhizal fungi trigger the expression of auxin-responsive genes, likely to suppress a salicylate-dependent signaling cascade [85]. Moreover, it seems that the alterations in the biosynthesis of glucosinolates led by Trichoderma treatment also have an impact on the flux of auxin biosynthesis [86,87]. Additionally, the auxin biosynthesis has an indirect effect on cytokinin homeostasis [86], creating a complex network of signalling; while, in the AMF treated plant, the presence of JAs play a role in glucosinolate regulation [88]. Considering the key role of glucosinolates on cell detoxification [89], it seems that both treatments enhanced cell resistance to ROS, even if by a differential pathway activation.

\section{Conclusions}

Tomato plants inoculated with either Arbuscular mycorrhizal fungi (AMF) or Trichoderma spp. displayed an increased leaf biomass index compared to the control, indicating a growth-promoting effect. Notwithstanding, a broad molecular cell re-programming was also observed to include some common responses between the beneficial fungi, together with several distinctive responses. In particular, the phenylpropanoid biosynthetic pathway was strongly elicited, with the production of defense phenolics like coumarins, bis-noryangonin, anthocyanins, and their glycosylated form. Another important aspect was the remodelling of membrane lipids and the production of sphingolipids as signal molecules. At the same time, the shaping of phytohormone profiles resulted in the accumulation of auxins, cytokinins, and jasmonate (especially after treatment with Trichoderma). To conclude, this work unraveled a specific metabolic reprogramming that takes place in tomato plants, after inoculation with Trichoderma or AMF. Such broad modulation of the secondary metabolism paves the way towards sustainable solutions using these microorganisms to increase plant tolerance to adverse conditions, including biotic and abiotic stress.

Supplementary Materials: The following are available online at https://www.mdpi.com/article/ 10.3390/horticulturae7100394/s1. Table S1: The whole UHPLC-ESI/QTOF metabolomic dataset produced from tomato leaves of plants following treatment with either mycorrhiza or Trichoderma, including individual abundance and composite mass spectra for all the features; Table S2: Discriminant compounds identified by OPLS-DA supervised modeling using the Variable Importance in Projection (VIP) approach. Compounds are listed with the individual VIP score and its standard error; Table S3: Differential metabolites derived from ANOVA followed by fold-change (FC) analysis $(p<0.01$, Bonferroni multiple testing correction; FC > 1.5 following UHPLC-ESI/QTOF metabolomics) of tomato plants treated with either mycorrhiza or Trichoderma.

Author Contributions: Conceptualization, L.L. and M.T.; methodology, L.L.; validation, L.L., B.M.M.; formal analysis, G.I. and B.M.-M.; resources, L.L.; data curation, B.M.-M. and L.L.; writingoriginal draft preparation, G.I. and B.M.-M.; writing - review and editing, L.L. and M.T.; supervision, L.L. and M.T.; All authors have read and agreed to the published version of the manuscript.

Funding: This research received no external funding.

Institutional Review Board Statement: Not applicable.

Informed Consent Statement: Not applicable.

Data Availability Statement: Data is contained within supplementary material. 
Acknowledgments: The authors wish to thank the "Romeo ed Enrica Invernizzi" foundation, Milan (Italy), for its kind support of the metabolomics facility. G.I. was the recipient of a PhD fellowship from the AgriSystem PhD school, Università Cattolica del Sacro Cuore. B.M.M. was the recipient of a postdoctoral contract for the training and improvement abroad of research staff (Begoña MirasMoreno; 21252/PD/19) financed by the Consejería de Empleo, Universidades, Empresa y Medio Ambiente of the CARM, through the Fundación Séneca-Agencia de Ciencia y Tecnología de la Región de Murcia (Spain).

Conflicts of Interest: The authors declare no conflict of interest.

\section{References}

1. Arora, N.K.; Fatima, T.; Mishra, I.; Verma, S. Microbe-based Inoculants: Role in Next Green Revolution. In Environmental Concerns and Sustainable Development: Volume 2: Biodiversity, Soil and Waste Management; Springer: Singapore, 2019 ; ISBN 9789811363580.

2. du Jardin, P. Plant biostimulants: Definition, concept, main categories and regulation. Sci. Hortic. 2015, 196, 3-14. [CrossRef]

3. Rouphael, Y.; Lucini, L.; Miras-Moreno, B.; Colla, G.; Bonini, P.; Cardarelli, M. Metabolomic Responses of Maize Shoots and Roots Elicited by Combinatorial Seed Treatments with Microbial and Non-microbial Biostimulants. Front. Microbiol. 2020, 11, 664. [CrossRef] [PubMed]

4. Tanwar, A.; Aggarwal, A.; Panwar, V. Arbuscular mycorrhizal fungi and Trichoderma viride mediated Fusarium wilt control in tomato. Biocontrol Sci. Technol. 2013, 23, 485-498. [CrossRef]

5. Al-Karaki, G.N. Nursery inoculation of tomato with arbuscular mycorrhizal fungi and subsequent performance under irrigation with saline water. Sci. Hortic. 2006, 109, 1-7. [CrossRef]

6. Baum, C.; El-Tohamy, W.; Gruda, N. Increasing the productivity and product quality of vegetable crops using arbuscular mycorrhizal fungi: A review. Sci. Hortic. 2015, 187, 131-141. [CrossRef]

7. Perelló, A.; Mónaco, C.; Simón, M.; Sisterna, M.R.; Dal Bello, G. Biocontrol efficacy of Trichoderma isolates for tan spot of wheat in Argentina. Crop. Prot. 2003, 22, 1099-1106. [CrossRef]

8. Verma, M.; Brar, S.K.; Tyagi, R.D.; Sahai, V.; Prévost, D.; Valéro, J.R.; Surampalli, R.Y. Bench-scale fermentation of Trichoderma viride on wastewater sludge: Rheology, lytic enzymes and biocontrol activity. Enzym. Microb. Technol. 2007, 41, 764-771. [CrossRef]

9. Rouphael, Y.; Franken, P.; Schneider, C.; Schwarz, D.; Giovannetti, M.; Agnolucci, M.; De Pascale, S.; Bonini, P.; Colla, G. Arbuscular mycorrhizal fungi act as biostimulants in horticultural crops. Sci. Hortic. 2015, 196, 91-108. [CrossRef]

10. López-Bucio, J.; Pelagio-Flores, R.; Herrera-Estrella, A. Trichoderma as biostimulant: Exploiting the multilevel properties of a plant beneficial fungus. Sci. Hortic. 2015, 196, 109-123. [CrossRef]

11. Rouphael, Y.; Colla, G. Synergistic Biostimulatory Action: Designing the Next Generation of Plant Biostimulants for Sustainable Agriculture. Front. Plant Sci. 2018, 9, 1655. [CrossRef]

12. Formisano, L.; Miras-Moreno, B.; Ciriello, M.; El-Nakhel, C.; Corrado, G.; Lucini, L.; Colla, G.; Rouphael, Y. Trichoderma and Phosphite Elicited Distinctive Secondary Metabolite Signatures in Zucchini Squash Plants. Agronomy 2021, 11, 1205. [CrossRef]

13. Bonini, P.; Rouphael, Y.; Miras-Moreno, B.; Lee, B.; Cardarelli, M.; Erice, G.; Cirino, V.; Lucini, L.; Colla, G. A Microbial-Based Biostimulant Enhances Sweet Pepper Performance by Metabolic Reprogramming of Phytohormone Profile and Secondary Metabolism. Front. Plant Sci. 2020, 11, 567388. [CrossRef]

14. Nanjundappa, A.; Bagyaraj, D.J.; Saxena, A.K.; Kumar, M.; Chakdar, H. Interaction between arbuscular mycorrhizal fungi and Bacillus spp. in soil enhancing growth of crop plants. Fungal Biol. Biotechnol. 2019, 6, 23. [CrossRef]

15. Pehlivan, N.; Saruhan-Güler, N.; Alpay-Karaoğlu, Ş. The Effect of Trichoderma Seed Priming to Drought Resistance in Tomato (Solanum lycopersicum L.) Plants. Hacet. J. Biol. Chem. 2018, 2, 263-272. [CrossRef]

16. Cameron, D.D.; Neal, A.L.; Van Wees, S.C.M.; Ton, J. Mycorrhiza-induced resistance: More than the sum of its parts? Trends Plant Sci. 2013, 18, 539-545. [CrossRef]

17. Yakhin, O.I.; Lubyanov, A.A.; Yakhin, I.A.; Brown, P.H. Biostimulants in Plant Science: A Global Perspective. Front. Plant Sci. 2017, 7, 2049. [CrossRef]

18. Dorais, M.; Ehret, D.L.; Papadopoulos, A.P. Tomato (Solanum lycopersicum) health components: From the seed to the consumer. Phytochem. Rev. 2008, 7, 231-250. [CrossRef]

19. The State of Food and Agriculture; FAO: Roma, Italy, 2019.

20. Paul, K.; Sorrentino, M.; Lucini, L.; Rouphael, Y.; Cardarelli, M.; Bonini, P.; Miras Moreno, M.B.; Reynaud, H.; Canaguier, R.; Trtílek, M.; et al. A Combined Phenotypic and Metabolomic Approach for Elucidating the Biostimulant Action of a Plant-Derived Protein Hydrolysate on Tomato Grown Under Limited Water Availability. Front. Plant Sci. 2019, 10, 493. [CrossRef] [PubMed]

21. Lucini, L.; Colla, G.; Miras-Moreno, B.; Bernardo, L.; Cardarelli, M.; Terzi, V.; Bonini, P.; Rouphael, Y. Inoculation of Rhizoglomus irregulare or Trichoderma atroviride differentially modulates metabolite profiling of wheat root exudates. Phytochemistry 2019, 157, 158-167. [CrossRef]

22. Lucini, L.; Miras-Moreno, B.; Rouphael, Y.; Cardarelli, M.; Colla, G. Combining Molecular Weight Fractionation and Metabolomics to Elucidate the Bioactivity of Vegetal Protein Hydrolysates in Tomato Plants. Front. Plant Sci. 2020, 11, 976. [CrossRef] 
23. Mimmo, T.; Tiziani, R.; Valentinuzzi, F.; Lucini, L.; Nicoletto, C.; Sambo, P.; Scampicchio, M.; Pii, Y.; Cesco, S. Selenium Biofortification in Fragaria $\times$ ananassa: Implications on Strawberry Fruits Quality, Content of Bioactive Health Beneficial Compounds and Metabolomic Profile. Front. Plant Sci. 2017, 8, 1887. [CrossRef]

24. Salek, R.M.; Neumann, S.; Schober, D.; Hummel, J.; Billiau, K.; Kopka, J.; Correa, E.; Reijmers, T.; Rosato, A.; Tenori, L.; et al. COordination of Standards in MetabOlomicS (COSMOS): Facilitating integrated metabolomics data access. Metabolomics 2015, 11, 1587-1597. [CrossRef] [PubMed]

25. Tsugawa, H.; Cajka, T.; Kind, T.; Ma, Y.; Higgins, B.; Ikeda, K.; Kanazawa, M.; VanderGheynst, J.; Fiehn, O.; Arita, M. MS-DIAL: Data-independent MS/MS deconvolution for comprehensive metabolome analysis. Nat. Methods 2015, 12, 523-526. [CrossRef] [PubMed]

26. Lai, Z.; Tsugawa, H.; Wohlgemuth, G.; Mehta, S.; Mueller, M.; Zheng, Y.; Ogiwara, A.; Meissen, J.; Showalter, M.; Takeuchi, K.; et al. Identifying metabolites by integrating metabolome databases with mass spectrometry cheminformatics. Nat. Methods 2018, 15, 53-56. [CrossRef] [PubMed]

27. Tsugawa, H.; Ikeda, K.; Takahashi, M.; Satoh, A.; Mori, Y.; Uchino, H.; Okahashi, N.; Yamada, Y.; Tada, I.; Bonini, P.; et al. A lipidome atlas in MS-DIAL 4. Nat. Biotechnol. 2020, 38, 1159-1163. [CrossRef] [PubMed]

28. Miras-Moreno, B.; Corrado, G.; Zhang, L.; Senizza, B.; Righetti, L.; Bruni, R.; El-Nakhel, C.; Sifola, M.I.; Pannico, A.; De Pascale, S.; et al. The Metabolic Reprogramming Induced by Sub-optimal Nutritional and Light Inputs in Soilless Cultivated Green and Red Butterhead Lettuce. Int. J. Mol. Sci. 2020, 21, 6381. [CrossRef] [PubMed]

29. Caspi, R.; Dreher, K.; Karp, P.D. The challenge of constructing, classifying, and representing metabolic pathways. FEMS Microbiol. Lett. 2013, 345, 85-93. [CrossRef] [PubMed]

30. Szczałba, M.; Kopta, T.; Gąstoł, M.; Sękara, A. Comprehensive insight into arbuscular mycorrhizal fungi, Trichoderma spp. and plant multilevel interactions with emphasis on biostimulation of horticultural crops. J. Appl. Microbiol. 2019, 127, 630-647. [CrossRef]

31. Adams, P.; De-Leij, F.A.A.M.; Lynch, J.M. Trichoderma harzianum Rifai 1295-22 Mediates Growth Promotion of Crack Willow (Salix fragilis) Saplings in Both Clean and Metal-Contaminated Soil. Microb. Ecol. 2007, 54, 306-313. [CrossRef] [PubMed]

32. Chang, Y.-C. Increased Growth of Plants in the Presence of the Biological Control Agent Trichoderma harzianum. Plant Dis. 1986, 70, 145. [CrossRef]

33. Contreras-Cornejo, H.A.; Macías-Rodríguez, L.; Cortés-Penagos, C.; López-Bucio, J. Trichoderma virens, a Plant Beneficial Fungus, Enhances Biomass Production and Promotes Lateral Root Growth through an Auxin-Dependent Mechanism in Arabidopsis. Plant Physiol. 2009, 149, 1579-1592. [CrossRef] [PubMed]

34. Colla, G.; Rouphael, Y.; Di Mattia, E.; El-Nakhel, C.; Cardarelli, M. Co-inoculation of Glomus intraradices and Trichoderma atroviride acts as a biostimulant to promote growth, yield and nutrient uptake of vegetable crops. J. Sci. Food Agric. 2015, 95, 1706-1715. [CrossRef]

35. Fiorentino, N.; Ventorino, V.; Woo, S.L.; Pepe, O.; De Rosa, A.; Gioia, L.; Romano, I.; Lombardi, N.; Napolitano, M.; Colla, G.; et al. Trichoderma-Based Biostimulants Modulate Rhizosphere Microbial Populations and Improve N Uptake Efficiency, Yield, and Nutritional Quality of Leafy Vegetables. Front. Plant Sci. 2018, 9, 743. [CrossRef]

36. Latef, A.A.H.A.; Hashem, A.; Rasool, S.; Abd-Allah, E.F.; Alqarawi, A.A.; Egamberdieva, D.; Jan, S.; Anjum, N.A.; Ahmad, P. Arbuscular mycorrhizal symbiosis and abiotic stress in plants: A review. J. Plant Biol. 2016, 59, 407-426. [CrossRef]

37. Pozo, M.J.; Azcón-Aguilar, C. Unraveling mycorrhiza-induced resistance. Curr. Opin. Plant Biol. 2007, 10, 393-398. [CrossRef]

38. Matos, M.J.; Santana, L.; Uriarte, E.; Abreu, O.A.; Molina, E.; Yordi, E.G. Coumarins-An Important Class of Phytochemicals. In Phytochemicals-Isolation, Characterisation and Role in Human Health; InTechOpen: London, UK, 2015. [CrossRef]

39. Bourgaud, F.; Hehn, A.; Larbat, R.; Doerper, S.; Gontier, E.; Kellner, S.; Matern, U. Biosynthesis of coumarins in plants: A major pathway still to be unravelled for cytochrome P450 enzymes. Phytochem. Rev. 2006, 5, 293-308. [CrossRef]

40. Kumar, P.; Jaiswal, V.; Pal, T.; Singh, J.; Chauhan, R.S. Comparative whole-transcriptome analysis in Podophyllum species identifies key transcription factors contributing to biosynthesis of podophyllotoxin in P. hexandrum. Protoplasma 2016, 254, 217-228. [CrossRef]

41. Zhao, P.; Li, Q.; Li, J.; Wang, L.; Ren, Z. Genome-wide identification and characterization of R2R3MYB family in Solanum lycopersicum. Mol. Genet. Genom. 2014, 289, 1183-1207. [CrossRef] [PubMed]

42. Liu, Y.; Tikunov, Y.; Schouten, R.E.; Marcelis, L.F.M.; Visser, R.G.F.; Bovy, A. Anthocyanin Biosynthesis and Degradation Mechanisms in Solanaceous Vegetables: A Review. Front. Chem. 2018, 6, 52. [CrossRef]

43. Lingua, G.; Bona, E.; Manassero, P.; Marsano, F.; Todeschini, V.; Cantamessa, S.; Copetta, A.; D’Agostino, G.; Gamalero, E.; Berta, G. Arbuscular Mycorrhizal Fungi and Plant Growth-Promoting Pseudomonads Increases Anthocyanin Concentration in Strawberry Fruits (Fragaria $\times$ ananassa var. Selva) in Conditions of Reduced Fertilization. Int. J. Mol. Sci. 2013, 14, 16207-16225. [CrossRef]

44. Lombardi, N.; Caira, S.; Troise, A.D.; Scaloni, A.; Vitaglione, P.; Vinale, F.; Marra, R.; Salzano, A.M.; Lorito, M.; Woo, S.L. Trichoderma Applications on Strawberry Plants Modulate the Physiological Processes Positively Affecting Fruit Production and Quality. Front. Microbiol. 2020, 11, 1364. [CrossRef]

45. Choudhary, D.K.; Prakash, A.; Johri, B.N. Induced systemic resistance (ISR) in plants: Mechanism of action. Indian J. Microbiol. 2007, 47, 289-297. [CrossRef] [PubMed] 
46. Heil, M.; Bostock, R.M. Induced systemic resistance (ISR) against pathogens in the context of induced plant defences. Ann. Bot. 2002, 89, 503-512. [CrossRef] [PubMed]

47. Ahuja, I.; Kissen, R.; Bones, A.M. Phytoalexins in defense against pathogens. Trends Plant Sci. 2012, 17, 73-90. [CrossRef] [PubMed]

48. Eckardt, N.A. Induction of Phytoalexin Biosynthesis: WRKY33 Is a Target of MAPK Signaling. Plant Cell 2011, 23, 1190. [CrossRef]

49. Arruda, R.L.; Paz, A.T.S.; Bara, M.T.F.; Côrtes, M.V.D.C.B.; De Filippi, M.C.C.; Da Conceição, E.C. An approach on phytoalexins: Function, characterization and biosynthesis in plants of the family Poaceae. Ciência Rural 2016, 46, 1206-1216. [CrossRef]

50. Morita, H.; Noguchi, H.; Schröder, J.; Abe, I. Novel polyketides synthesized with a higher plant stilbene synthase. Eur. J. Biol. 2001, 268, 3759-3766. [CrossRef]

51. Hain, R.; Reif, H.-J.; Krause, E.; Langebartels, R.; Kindl, H.; Vornam, B.; Wiese, W.; Schmelzer, E.; Schreier, P.H.; Stöcker, R.H.; et al. Disease resistance results from foreign phytoalexin expression in a novel plant. Nature 1993, 361, 153-156. [CrossRef]

52. Soleas, G.J.; Diamandis, E.P.; Goldberg, D.M. Resveratrol: A molecule whose time has come? And gone? Clin. Biochem. 1997, 30, 91-113. [CrossRef]

53. Langcake, P.; Cornford, C.A.; Pryce, R.J. Identification of pterostilbene as a phytoalexin from Vitis vinifera leaves. Phytochemistry 1979, 18, 1025-1027. [CrossRef]

54. Ongena, M.; Daayf, F.; Jacques, P.; Thonart, P.; Benhamou, N.; Paulitz, T.C.; Bélanger, R.R. Systemic induction of phytoalexins in cucumber in response to treatments with fluorescent Pseudomonads. Plant Pathol. 2000, 49, 523-530. [CrossRef]

55. Pršić, J.; Ongena, M. Elicitors of Plant Immunity Triggered by Beneficial Bacteria. Front. Plant Sci. 2020, 11, 594530. [CrossRef] [PubMed]

56. Hao, Z.; Xie, W.; Chen, B. Arbuscular Mycorrhizal Symbiosis Affects Plant Immunity to Viral Infection and Accumulation. Viruses 2019, 11, 534. [CrossRef] [PubMed]

57. Vogt, T. Phenylpropanoid biosynthesis. Mol. Plant 2010, 3, 2-20. [CrossRef] [PubMed]

58. Hamberger, B.; Ellis, M.; Friedmann, M.; Souza, C.D.A.; Barbazuk, B.; Douglas, C.J. Genome-wide analyses of phenylpropanoidrelated genes in Populus trichocarpa, Arabidopsis thaliana, and Oryza sativa: The Populus lignin toolbox and conservation and diversification of angiosperm gene families. Can. J. Bot. 2007, 85, 1182-1201. [CrossRef]

59. Brader, G.; Tas, E.; Palva, E.T. Jasmonate-Dependent Induction of Indole Glucosinolates in Arabidopsis by Culture Filtrates of the Nonspecific Pathogen Erwinia carotovora. Plant Physiol. 2001, 126, 849-860. [CrossRef] [PubMed]

60. Nejat, N.; Mantri, N. Plant Immune System: Crosstalk Between Responses to Biotic and Abiotic Stresses the Missing Link in Understanding Plant Defence. Curr. Issues Mol. Biol. 2017, 23, 1-16. [CrossRef]

61. Lucini, L.; Rouphael, Y.; Cardarelli, M.; Bonini, P.; Baffi, C.; Colla, G. A Vegetal Biopolymer-Based Biostimulant Promoted Root Growth in Melon While Triggering Brassinosteroids and Stress-Related Compounds. Front. Plant Sci. 2018, 9, 472. [CrossRef]

62. Rogowska, A.; Szakiel, A. The role of sterols in plant response to abiotic stress. Phytochem. Rev. 2020, 19, 1525-1538. [CrossRef]

63. Ron, M.; Avni, A. The Receptor for the Fungal Elicitor Ethylene-Inducing Xylanase Is a Member of a Resistance-Like Gene Family in Tomato. Plant Cell 2004, 16, 1604-1615. [CrossRef]

64. Bailey, B.A.; Dean, J.F.D.; Anderson, J.D. An Ethylene Biosynthesis-Inducing Endoxylanase Elicits Electrolyte Leakage and Necrosis in Nicotiana tabacum cv Xanthi Leaves. Plant Physiol. 1990, 94, 1849-1854. [CrossRef] [PubMed]

65. Ron, M.; Kantety, R.; Martin, G.B.; Avidan, N.; Eshed, Y.; Zamir, D.; Avni, A. High-resolution linkage analysis and physical characterization of the EIX-responding locus in tomato. Theor. Appl. Genet. 2000, 100, 184-189. [CrossRef]

66. Sharfman, M.; Bar, M.; Schuster, S.; Leibman, M.; Avni, A. Sterol-dependent induction of plant defense responses by a microbeassociated molecular pattern from Trichoderma viride. Plant Physiol. 2014, 164, 819-827. [CrossRef]

67. Xue, H.-W.; Chen, X.; Mei, Y. Function and regulation of phospholipid signalling in plants. Biochem. J. 2009, 421, 145-156. [CrossRef] [PubMed]

68. Ali, U.; Li, H.; Wang, X.; Guo, L. Emerging Roles of Sphingolipid Signaling in Plant Response to Biotic and Abiotic Stresses. Mol. Plant 2018, 11, 1328-1343. [CrossRef]

69. Siebers, M.; Brands, M.; Wewer, V.; Duan, Y.; Hölzl, G.; Dörmann, P. Lipids in plant-microbe interactions. Biochim. Biophys. Acta (BBA) Mol. Cell Biol. Lipids 2016, 1861, 1379-1395. [CrossRef] [PubMed]

70. Xing, J.; Zhang, L.; Duan, Z.; Lin, J. Coordination of Phospholipid-Based Signaling and Membrane Trafficking in Plant Immunity. Trends Plant Sci. 2021, 26, 407-420. [CrossRef] [PubMed]

71. Bari, R.; Jones, J.D.G. Role of plant hormones in plant defence responses. Plant Mol. Biol. 2009, 69, 473-488. [CrossRef] [PubMed]

72. Perez-Alonso, M.M.; Pollmann, S. How Auxin May Contribute to the Regulation of Plant Defense Responses against Herbivory. Austin J. Plant Biol. 2018, 4, 1019. [CrossRef]

73. Müller, B.; Sheen, J. Arabidopsis Cytokinin Signaling Pathway. Sci. STKE 2007, 2007, cm5. [CrossRef]

74. Gupta, R.; Pizarro, L.; Leibman-Markus, M.; Marash, I.; Bar, M. Cytokinin response induces immunity and fungal pathogen resistance, and modulates trafficking of the PRR LeEIX2 in tomato. Mol. Plant Pathol. 2020, 21, 1287-1306. [CrossRef]

75. Onkokesung, N.; Gális, I.; von Dahl, C.C.; Matsuoka, K.; Saluz, H.-P.; Baldwin, I.T. Jasmonic Acid and Ethylene Modulate Local Responses to Wounding and Simulated Herbivory in Nicotiana attenuata Leaves. Plant Physiol. 2010, 153, 785-798. [CrossRef]

76. Pieterse, C.M.J.; Van Wees, S.C.M.; Van Pelt, J.A.; Knoester, M.; Laan, R.; Gerrits, H.; Weisbeek, P.J.; Van Loon, L.C. A Novel Signaling Pathway Controlling Induced Systemic Resistance in Arabidopsis. Plant Cell 1998, 10, 1571-1580. [CrossRef] [PubMed] 
77. Hayat, Q.; Hayat, S.; Ali, B.; Ahmad, A. Auxin Analogues and Nitrogen Metabolism, Photosynthesis, and Yield of Chickpea. J. Plant Nutr. 2009, 32, 1469-1485. [CrossRef]

78. Kiba, T.; Kudo, T.; Kojima, M.; Sakakibara, H. Hormonal control of nitrogen acquisition: Roles of auxin, abscisic acid, and cytokinin. J. Exp. Bot. 2010, 62, 1399-1409. [CrossRef] [PubMed]

79. Denancé, N.; Sánchez-Vallet, A.; Goffner, D.; Molina, A. Disease resistance or growth: The role of plant hormones in balancing immune responses and fitness costs. Front. Plant Sci. 2013, 4, 155. [CrossRef] [PubMed]

80. Navarro, L.; Dunoyer, P.; Jay, F.; Arnold, B.; Dharmasiri, N.; Estelle, M.; Voinnet, O.; Jones, J.D.G. A Plant miRNA Contributes to Antibacterial Resistance by Repressing Auxin Signaling. Science 2006, 312, 436-439. [CrossRef] [PubMed]

81. Etemadi, M.; Gutjahr, C.; Couzigou, J.M.; Zouine, M.; Lauressergues, D.; Timmers, A.; Audran, C.; Bouzayen, M.; Bécard, G.; Combier, J.P. Auxin perception is required for arbuscule development in arbuscular mycorrhizal symbiosis. Plant Physiol. 2014, 166, 281-292. [CrossRef] [PubMed]

82. Liao, D.; Chen, X.; Chen, A.; Wang, H.; Liu, J.; Liu, J.; Gu, M.; Sun, S.; Xu, G. The Characterization of Six Auxin-Induced Tomato GH3 Genes Uncovers a Member, SlGH3.4, Strongly Responsive to Arbuscular Mycorrhizal Symbiosis. Plant Cell Physiol. 2015, 56, 674-687. [CrossRef]

83. Laffont, C.; Rey, T.; André, O.; Novero, M.; Kazmierczak, T.; Debelle, F.; Bonfante, P.; Jacquet, C.; Frugier, F. The CRE1 Cytokinin Pathway Is Differentially Recruited Depending on Medicago truncatula Root Environments and Negatively Regulates Resistance to a Pathogen. PLoS ONE 2015, 10, e0116819. [CrossRef]

84. Fusconi, A. Regulation of root morphogenesis in arbuscular mycorrhizae: What role do fungal exudates, phosphate, sugars and hormones play in lateral root formation? Ann. Bot. 2014, 113, 19-33. [CrossRef] [PubMed]

85. Plett, J.M.; Kemppainen, M.; Kale, S.D.; Kohler, A.; Legué, V.; Brun, A.; Tyler, B.M.; Pardo, A.G.; Martin, F. A Secreted Effector Protein of Laccaria bicolor Is Required for Symbiosis Development. Curr. Biol. 2011, 21, 1197-1203. [CrossRef] [PubMed]

86. Grubb, C.D.; Abel, S. Glucosinolate metabolism and its control. Trends Plant Sci. 2006, 11, 89-100. [CrossRef] [PubMed]

87. Ludwig-Müller, J. Glucosinolates and the clubroot disease: Defense compounds or auxin precursors? Phytochem. Rev. 2008, 8, 135-148. [CrossRef]

88. Mitreiter, S.; Gigolashvili, T. Regulation of glucosinolate biosynthesis. J. Exp. Bot. 2021, 72, 70-91. [CrossRef]

89. Sun, R.; Gols, R.; Harvey, J.A.; Reichelt, M.; Gershenzon, J.; Pandit, S.S.; Vassão, D.G. Detoxification of plant defensive glucosinolates by an herbivorous caterpillar is beneficial to its endoparasitic wasp. Mol. Ecol. 2020, 29, 4014-4031. [CrossRef] [PubMed] 